\title{
Photocatalytic oxidation of fuel oxygenated additives in aqueous solutions
}

\author{
M. Krichevskaya, ${ }^{1}$ A. Kachina, ${ }^{2}$ T. Malygina, ${ }^{2}$ \\ S. Preis, ${ }^{3}$ and J. Kallas ${ }^{3}$ \\ ${ }^{1}$ Institute of Chemistry at Tallinn Technical University, 15 Akadeemia tee, Tallinn 12618, Estonia \\ 2 Tallinn Technical University, 5 Ehitajate tee, Tallinn 19086, Estonia \\ ${ }^{3}$ Lappeenranta University of Technology, P. O. Box 20, Lappeenranta 53851, Finland
}

\begin{abstract}
Experimental research of photocatalytical oxidation (PCO) of aqueous solutions of de-icing agents (ethylene glycol and ethylene glycol monoethyl ether) and methyl tert-butyl ether (MTBE) was undertaken. These chemicals are water-soluble components of jet and motor fuels accidentally disposed to the environment. Titanium dioxide (Degussa P25) under near-UV irradiation was selected as a photocatalyst. A slightly acidic medium was preferable for the process efficiency for MTBE, whereas a neutral medium was beneficial for de-icing agents and jet fuel aqueous extracts. $\mathrm{TiO}_{2}$ suspension fractional composition was found to be dependent on $\mathrm{pH}$ and the presence of organic admixtures: the minimum size of $\mathrm{TiO}_{2} \mathrm{par}^{-}$ ticles at their maximum uniformity was established in an acidic medium, where the efficiency of PCO of de-icing agents was the poorest. On the other hand, neutral and slightly acidic media, beneficial for PCO efficiency, were favourable for particle agglomeration, which indicates a minimal role for photocatalyst particle size in PCO efficiency. PCO efficiency increased with increasing MTBE and icing inhibitor concentration. The biodegradability of aqueous solutions of oxygenated additives increased as PCO proceeded. The influence of mineral additives - sulphate, calcium, ferric and manganese ions-on the process efficiency was found to be complex. Special attention was paid to energy-saving PCO with a photocatalyst attached to buoyant glass micro-spheres and reduced intensity of stirring of the slurry.
\end{abstract}

\section{INTRODUCTION}

Improper handling of jet fuel at an abandoned military base in Estonia has resulted in heavy pollution of the soil and groundwater [1]. Icing inhibitors-basically ethylene glycol and its derivatives-being toxic compounds miscible with water and constituting up to $1 \%$ vol. of jet fuel [2] contribute significantly to the pollution. Abatement strategies for fuel hydrocarbons as water pollutants such as kerosene recovery, air stripping, steam distillation and microbial degradation are unlikely to be effective in the removal of icing inhibitors.

Methyl tert-butyl ether (MTBE) was the most widely used gasoline additive until 1998 in the USA and is still the basic oxygenated additive used nowadays in the rest of the world. MTBE occurs in groundwater as a result of leakage from storage tanks and pipelines, simple spills from tank overfilling at gasoline dispense stations or from car accidents, and homeowner releases [3]. MTBE degrades very slowly in soils and groundwater [4-7]. Air stripping is a traditional and reliable technology for the removal of VOCs from groundwater but needs additional arrangements for MTBE [4, 8], which has a comparatively low Henry's Law constant. In addition, the exhaust air from strippers has to be treated to avoid MTBE release to the atmosphere.

Although the available information shows that a wide spectrum of organic compounds yields to PCO, little information is available on the aqueous PCO of glycol and its ethers, and MTBE. The study of aqueous
PCO of oxygenates has the objective of establishing the feasibility of the method and considers factors influencing the process: $\mathrm{pH}$, concentration of pollutants and photocatalyst application mode.

The influence of mineral ions such as sulphate, manganese and ferric ions on the PCO rate of MTBE was also studied. Data available from published sources do not give unequivocal information about the role of these ions in PCO efficiency.

There are data on improving the performance of PCO of chlorophenols by adding manganese ions [9] leading to an increase in photo-generated electrons and holes and inhibiting electron-hole recombination, while [10] showed the detrimental effect of the same ion on phenol degradation. Simultaneously, [10] observed a significant decrease in phenol's half-life time in the presence of ferric ions in concentrations up to $0.57 \mathrm{mM}$. A further increase in the concentration of dissolved ferric ions did not improve the rate of phenol degradation. The formation of $\mathrm{Fe}^{2+}$-ions was confirmed as a result of irradiation of photocatalytic $\mathrm{TiO}_{2}$-systems containing $\mathrm{Fe}^{3+}$-ions.

The initial rate of PCO of 3-chlorophenol under pH 8.0 was indifferent to addition of sodium sulphate at a concentration of $0.155 \mathrm{mM}$. Under acidic conditions, a decrease in the initial rate of PCO was observed in the presence of sulphate [11]. The presence of sulphate ions at $\mathrm{pH} 6.8$, where they are in $\mathrm{HSO}_{4}{ }^{-}$form, was expected to decrease the reaction rates of humic acid PCO, however, a slight increase in the reaction rate constant 
was observed [12]. [13] reported that the rate of PCO of monocrotophos increased with increasing sulphate concentration.

\section{METHODS}

Experiments were carried out using solutions of ethylene glycol, ethylene glycol monoethyl ether (2ethoxyethanol, 2-EE) and MTBE as well as aqueous extracts of commercial jet fuel. If not otherwise specified, concentrations of icing inhibitors were chosen to provide chemical oxygen demand (COD) of synthetic solutions as big as $200 \mathrm{mg} \mathrm{O}_{2} / \mathrm{l}$. COD of the jet fuel aqueous extract ranged between 170 and $200 \mathrm{mg} \mathrm{O} / \mathrm{l}$. The concentration of MTBE synthetic solution was $100 \mathrm{mg} / \mathrm{l}$, if not otherwise specified. PCO experiments were performed in a $0.20 \mathrm{l}$ capacity thermostatted batch glass reactor, having an inner diameter $100 \mathrm{~mm}$, and thus an exposed surface to volume ratio (aperture) equal to $39.3 \mathrm{~m}^{2} / \mathrm{m}^{3}$, supplied with a magnetic stirrer. The revolution frequency of a standard $25-\mathrm{mm}$ stirrer was $300 \mathrm{rev} / \mathrm{min}$. All experiments were compared with reference samples, treated under identical conditions except UV-radiation. A $365 \mathrm{~nm}$ UV-lamp was positioned horizontally over the reactor (irradiance was about $1.1 \mathrm{~mW} / \mathrm{cm}^{2}$, measured by UVX Radiometer). PCO was performed in two ways: catalysed by irradiated $\mathrm{TiO}_{2}$ slurry (Degussa P25, $1 \mathrm{~g} / \mathrm{l}$ ) or by $\mathrm{TiO}_{2}$ attached to buoyant hollow glass micro-spheres (the product of LPImpEx, Estonia). Titanium dioxide was attached to the surface of the micro-beads by thermal method [14]. The $\mathrm{pH}$ value was controlled by the addition of either sulphuric acid or sodium hydroxide. The samples, saturated with calcium hydroxide by the addition of $5 \mathrm{~g} / \mathrm{l}$ of $\mathrm{CaO}$ prior to the onset of photocatalytic treatment, had a stable $\mathrm{pH}$ of around 12.5 and were treated without pH control. Tert-butanol (TBA) was added at the very beginning of the experiments in molar equivalent amount regarding the concentration of a target compound. All experiments were conducted at $20 \pm 1{ }^{\circ} \mathrm{C}$. Following PCO, COD, total organic carbon (TOC) and biochemical oxygen demand $\left(\mathrm{BOD}_{7}\right)$ were determined. $\mathrm{COD}$ and $\mathrm{BOD}_{7}$ were measured by standard procedures [15]. TOC was determined with a Shimadzu 5050 A TOC analyser. The concentration of glycols and aldehydes, as oxidation by-products, were measured with 3-methyl2-benzothiazolinone hydrazone $\mathrm{HCl}$ hydrate by the method described by [16]. This method, suitable for measurement of glycol derivatives, appeared to be nonapplicable to straight measurement of MTBE and TBA. The fractional composition of $\mathrm{TiO}_{2}$ particles in slurry was determined by means of particle size analyser Coulter LS130.

\section{RESULTS AND DISCUSSION}

The performance of PCO with artificial radiation sources was characterised by the process efficiency $E$.
The efficiency $E$ was defined as the decrease in COD divided by the amount of energy reaching the surface of the treated sample:

$$
E=\frac{\Delta c \cdot V \cdot 1000}{I \cdot s \cdot t}
$$

$E$-PCO process efficiency, $\mathrm{mg} / \mathrm{Wh} ; \Delta c$-COD decrease, $\mathrm{mgO}_{2} / \mathrm{l} ; V$-the volume of sample to be treated, l; $I$ irradiation intensity, $\mathrm{mW} / \mathrm{cm}^{2} ; s$-solution irradiated surface area, $\mathrm{cm}^{2} ; t$-treatment time, h.

3.1. PCO performance and its mechanism. As was previously established, a neutral medium is preferable for maximum process efficiency for both de-icing agents and jet fuel aqueous extract [17]. For these compounds, an increase in $\mathrm{pH}$ from 6 to 11 did not result in a drastic increase in the PCO efficiency. This fact was attributed to the minor role $\mathrm{OH}^{\bullet}$-radicals play in PCO of icing inhibitors.

The result of PCO of MTBE solutions is presented in Figure 1 and shows that MTBE readily yields to PCO and the PCO efficiency varies with $\mathrm{pH}$.

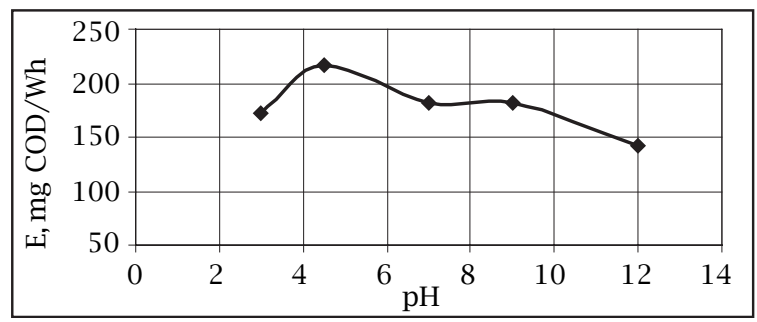

Figure 1. Dependence of PCO efficiency on $\mathrm{pH}$ for synthetic solution of MTBE (the efficiency is calculated for 1-hour treatment of MTBE solutions).

A slightly acidic medium ( $\mathrm{pH} 4.5)$ gives maximum PCO efficiency-215 mg COD/Wh. The efficiency increases with $\mathrm{pH}$ from 3.0 to 4.5 , decreases with further increase of $\mathrm{pH}$ up to 7.0, remains stable between 7.0 and 9.0 and then decreases further with $\mathrm{pH}$ growth up to 12.0 . As one can see, an alkaline medium, favourable for $\mathrm{OH}^{\bullet}$-radicals generation, is not auspicious for MTBE oxidation, which confirms the negligible role of $\mathrm{OH}^{\bullet}$ radicals in PCO of MTBE. Furthermore, the highest aldehyde concentrations were also detected in the alkaline medium (Figure 2). This is presumably conditioned by

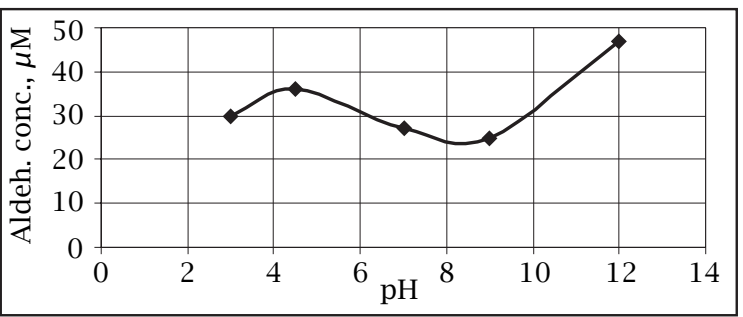

Figure 2. Dependence of aldehydes concentration on $\mathrm{pH}$ after $1 \mathrm{~h}$ of PCO of MTBE solution. 

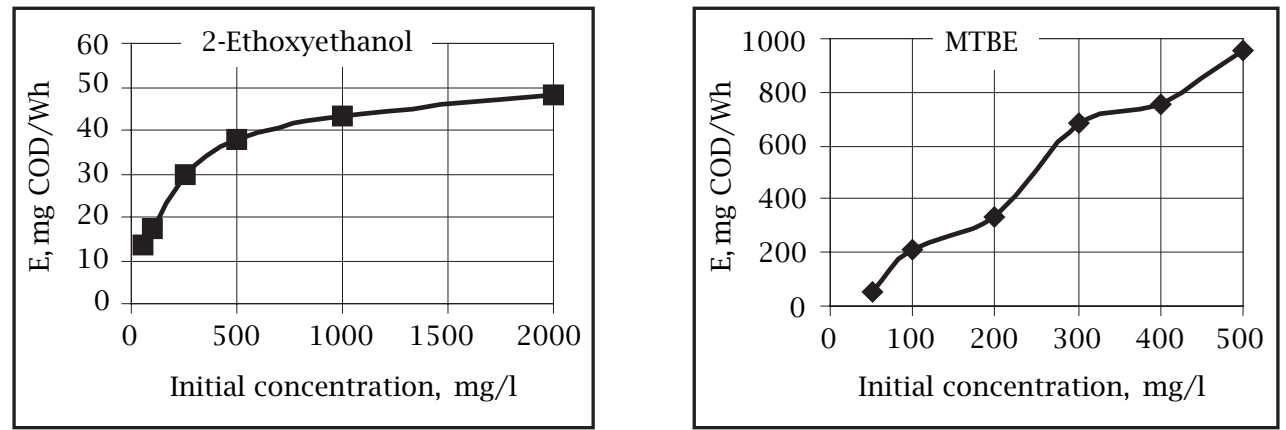

Figure 3. Dependence of PCO process efficiency on initial 2-EE and MTBE concentration.

the participation of $\mathrm{OH}^{\bullet}$-radicals in the chain of oxidation reactions, when aldehydes are formed.

TBA, well known as an $\mathrm{OH}^{\bullet}$-radicals scavenger, was added to $\mathrm{TiO}_{2}$ slurry at an amount of $82 \mathrm{mg} / \mathrm{l}$ when 2-EE with an initial concentration of $100 \mathrm{mg} / \mathrm{l}$ was oxidised. Preliminary experiments with TBA show that the efficiency of PCO of TBA in aqueous solutions is comparable by order of magnitude with that of 2-EE: at $\mathrm{pH}$ from 3.5 to 5.0 and an initial concentration of TBA of about $100 \mathrm{mg} / \mathrm{l}$ the efficiency was 20-22 mg COD/Wh, whereas for 2-EE PCO gives $18 \mathrm{mg}$ COD/Wh under analogous conditions. PCO of TBA showed the poorest performance in alkaline solution-10-12 mg COD/Wh. Nevertheless, the addition of TBA to the sample of 2EE solution under acidic and neutral media conditions had a smaller effect on the PCO efficiency of 2-EE (10$18 \%$ reduction), than in an alkaline medium (35\%). The effect of TBA addition in acidic and neutral media may be explained by competitive simultaneous oxidation of TBA and 2-EE.

3.2. Influence of concentration of substances to be oxidised. PCO of MTBE and 2-EE solutions with initial concentrations ranging from 50 to $500 \mathrm{mg} / \mathrm{l}$ (at $\mathrm{pH} 4.5$ ) and from 50 to $2000 \mathrm{mg} / \mathrm{l}$ (at pH 6) respectively were carried out. The dependencies of PCO efficiency on the initial concentration of MTBE and 2-EE are shown in Figure 3. The process efficiency increases with increasing pollutant concentration. Presumably, the maximum efficiency, usually observed with aromatic compounds [18], was not achieved within the experimental limits due to the absence of a UV-screening effect of the pollutants.

An increase in the aldehyde concentration with increasing initial concentration of MTBE was also observed. However, the ten-fold increase in MTBE initial concentration resulted in only a two-fold increase in aldehyde concentration. The disproportionate increase in aldehyde concentration could be explained by the difference in MTBE and aldehyde adsorption properties on the surface of titanium dioxide and, thus, faster oxidation of the latter.
3.3. Effect of mineral additives. By-products of PCO of organic compounds are often indicated as carbonic acids. Some of these may be removed from the reaction zone by being bound with calcium ions, forming insoluble salts. Therefore, the addition of $\mathrm{CaO}$ to the PCO reactor may result in a reduction in COD of the treated water. The presence of calcium hydroxide in the slurry noticeably increased-from $150 \mathrm{mg}$ COD/Wh at pH 12 adjusted with $\mathrm{NaOH}$ to $210 \mathrm{mg} \mathrm{COD} / \mathrm{Wh}$ at $\mathrm{pH}$ 12.5 adjusted with $\mathrm{CaO}$ - the PCO efficiency of MTBE, which may be explained by the forming of insoluble calcium salts of organic acids and their removal from the solution. After one-hour PCO of MTBE solution the concentration of aldehyde was $25 \mu \mathrm{mol} / \mathrm{l}$ in the presence of $\mathrm{Ca}(\mathrm{OH})_{2}$ and $50 \mu \mathrm{mol} / \mathrm{l}$ in the presence of $\mathrm{NaOH}$. This could be considered as evidence that PCO byproducts-precursors of aldehyde-are partially withdrawn from the solution as calcium compounds during the PCO.

When adding sulphate ions and sodium ions as counter-ions, at concentrations up to $100 \mathrm{mM}$ into $1.136 \mathrm{mM}(100 \mathrm{mg} / \mathrm{l}) \mathrm{MTBE}$ solution at $\mathrm{pH} \mathrm{3,5,7}$ and 10 , a decrease in PCO efficiency was observed. The decrease is greater when the concentration of the sulphate ion is higher at pH 3, 5 and 10. At pH 7 no such dependence was observed (Figure 4). At higher $\mathrm{pH}$ the surface charge of titanium dioxide is negative [11], consequently, anions are not expected to have much effect on

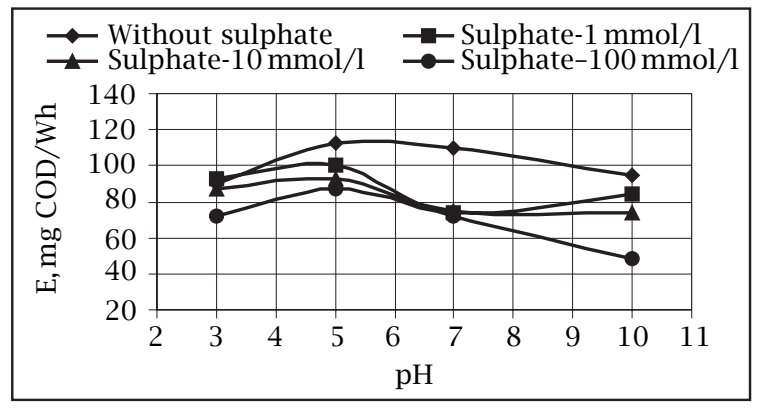

Figure 4. Dependence of MTBE PCO efficiency on $p H$ at different concentrations of $\mathrm{Na}_{2} \mathrm{SO}_{4}$ for 2-hours treatment. 
the degradation of an organic pollutant. Nevertheless, the presence of sulphate ions considerably retarded the PCO of MTBE in an alkaline medium. The behaviour of sulphate ions in neutral media may be explained by their adsorption at the titanium dioxide surface, which may be the best at this particular $\mathrm{pH}$ value. The adsorption of sulphate may be then an obstacle for adsorption of MTBE molecules to be oxidised.

The influence of multivalent metallic ions, such as ferric and manganese, on the PCO of MTBE was studied for concentrations up to $100 \mathrm{mM}$ at pH 3 (Figure 5). Sulphate was chosen as a counter-ion, being known as an anion of non-dramatic behaviour concerning MTBE PCO efficiency in an acidic medium. The addition of $1 \mathrm{mM}$ of manganese and ferric ions improved the PCO efficiency for the MTBE solution by $40 \%$ and $85 \%$ respectively. Further addition of these ions-from $1 \mathrm{mM}$ to $10 \mathrm{mM}$-however, swiftly reduces the PCO efficiency. Further addition of ferric and manganese ions-from 10 to $100 \mathrm{mM}$-gradually increases the efficiency of PCO of MTBE to a value approaching PCO efficiency in the absence of metallic ions. In the absence of titanium dioxide, no changes in MTBE concentration were observed under UV-radiation in the presence of $100 \mathrm{mM}$ of ferric or manganese ions.

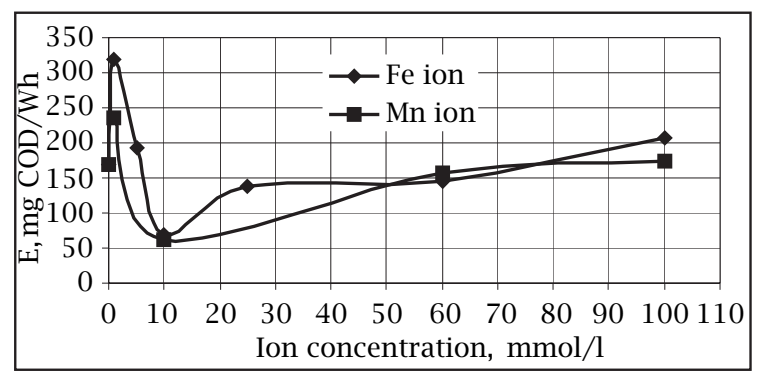

Figure 5. Dependence of MTBE PCO efficiencies on ferric and manganese ions concentration at $\mathrm{pH} 3$.

To explain such complex behaviour of PCO efficiency dependent on ferric and manganese ion concentration, the authors propose the following. The drastic increase in PCO efficiency at low concentrations of metallic ions could be attributed to the decrease in the recombination rate between positively charged holes and conductivity band electrons that is considered as the PCO limitation stage. Conductivity electrons may be "scavenged" by metallic ions at a higher oxidation stage and, thus, engaged outside the crystal structure of titanium dioxide. This makes the electronhole recombination slower and, therefore, oxidation of MTBE more probable. The decrease in PCO efficiency with further increase of metallic ion concentration is, presumably, caused by the competitive adsorption of the organic pollutant, oxygen and aquometallic ions, such as $\left[\mathrm{Fe}(\mathrm{OH})\left(\mathrm{H}_{2} \mathrm{O}\right)_{5}\right]^{2+}$, the dominant ferric iron species at $\mathrm{pH}$ from 2.5 to 5.0 , formed in the aqueous solutions [19]: aquometallic ions block the adsorption sites of titanium dioxide impeding access of organic molecules to be oxidised; the recombination of electrons and holes takes place within the layer of aquometallic ions close to the surface of the photocatalyst particles-“a short circuit"-with lessened MTBE oxidation rate. A similar situation was described in [13], when the PCO rate of monocrotophos increased in the presence of copper ions at concentrations lower than $10^{-5} \mathrm{M}$ and decreased in the presence of copper ions at concentrations higher than $10^{-5} \mathrm{M}$.

The restoration to its original level of the oxidative activity of titanium dioxide with further increasing concentration of metallic ions could be explained by the development of a different mechanism of oxidation, in which the aquometallic ions of iron and manganese become carriers of the oxidative positive charge originating from the hole at the titanium dioxide particle to the surface of the "blanket" formed by the aquometallic ions. The fact that no or only negligible traces of aldehyde were detected during PCO in the presence of ferric or manganese ions respectively serves as an indirect proof of the difference in oxidation mechanism with and without the metallic ions.

3.4. Energy-saving PCO. Special attention was paid to energy-saving PCO with reduced stirring of the slurry. The reduced stirring was applied in the form of episodic stirring for $7.5,15$ or $30 \mathrm{~min} / \mathrm{h}$, controlled by the timer switching the stirrer's appliance on and off. The aim was to establish the ability of $\mathrm{TiO}_{2}$ slurries to maintain PCO of sufficient efficiency without or with episodic stirring.

For the jet fuel aqueous extract, a 50\% loss in PCO efficiency was observed when no stirring was applied compared to constant stirring. More uniform smallsized $\mathrm{TiO}_{2}$ suspensions, attained in 2-EE solutions, gave only a $35 \%$ reduction in PCO efficiency for non-agitated slurries (Figure 6).

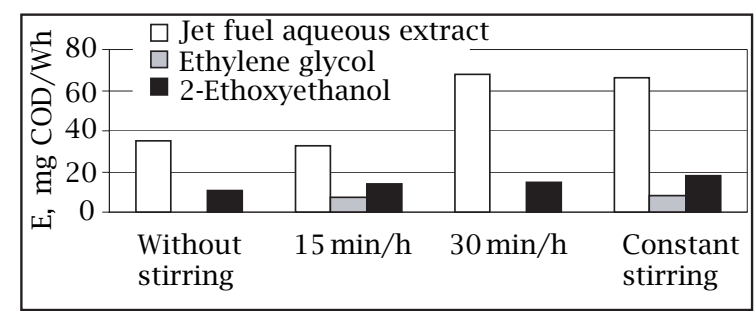

Figure 6. Dependence of jet fuel extract, ethylene glycol and 2-EE PCO efficiencies on stirring mode without $\mathrm{pH}$ regulation.

The influence of stirring mode on the PCO efficiency of 2-EE solutions was also studied for dependence on $\mathrm{pH}$. The decrease in PCO efficiency due to reduced stirring appeared to be independent of $\mathrm{pH}$ (see Figure 7). 


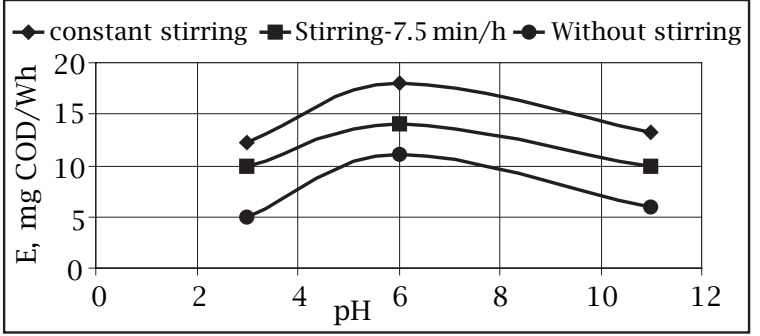

Figure 7. Dependence of 2-EE PCO efficiencies on different mixing modes and $\mathrm{pH}$.

An observation made during the work with $\mathrm{TiO}_{2}$ suspensions is worthy of mention. The particles of titanium dioxide with maximum uniformity and minimum size were observed in an acidic medium at $\mathrm{pH} 3.0-92 \%$ of size from 0 to $20 \mu \mathrm{m}$. However, the acidic medium appeared to be less effective in PCO of both de-icing agents and MTBE. Moreover, the titanium dioxide suspension in a 2-EE solution in a neutral or slightly acidic medium, favourable for PCO of icing inhibitors, contains a maximum fraction of coarse particles-15\% from 20 to $40 \mu \mathrm{m}$, which is natural for $\mathrm{TiO}_{2}$ suspensions at the isoelectric point [20]. This observation shows that the particle size distribution in $\mathrm{TiO}_{2}$ slurry, dependent on $\mathrm{pH}$, is unlikely to determine the PCO efficiency: the effect of $\mathrm{pH}$ is attributed to adsorption issues.

Monitoring of the $\mathrm{TiO}_{2}$ particle size during PCO of 2-EE indicated a flocculation character of PCO byproducts: the content of coarse particles increased as PCO proceeded, reached its maximum at the treated sample COD of $60-70 \%$ from the initial value and then decreased to the value characteristic for the suspension at the given $\mathrm{pH}$ with no organic admixtures.

3.5. PCO under solar radiation. UV-irradiance under solar radiation was not measured in the present research. Comparative experiments with samples, treated with a buoyant catalyst and non-agitated slurry under solar radiation (May to June 2001) showed that there was almost no difference in the rate of COD reduction in jet fuel aqueous extracts (Figure 8). During PCO of 2-EE solutions, the buoyant photocatalyst showed a lower activity than non-agitated slurry.

A drastic loss-about 50\%-in efficiency was observed as a result of the ceased stirring when PCO was applied to the jet fuel aqueous extract under artificial irradiation. The PCO efficiency of non-agitated slurry here approached the PCO efficiency of a buoyant photocatalyst. This may be explained by optical activity of the jet fuel aqueous extract in the UV range, partially screening the UV from penetration to the bottom of the reactor, where $\mathrm{TiO}_{2}$ particles settle in a hydrodynamically quiescent medium. This was established by spectro-photometric analysis of jet fuel aqueous extract. The UV-transparent solution of 2-EE exhibits no screening effect for radiation thus making
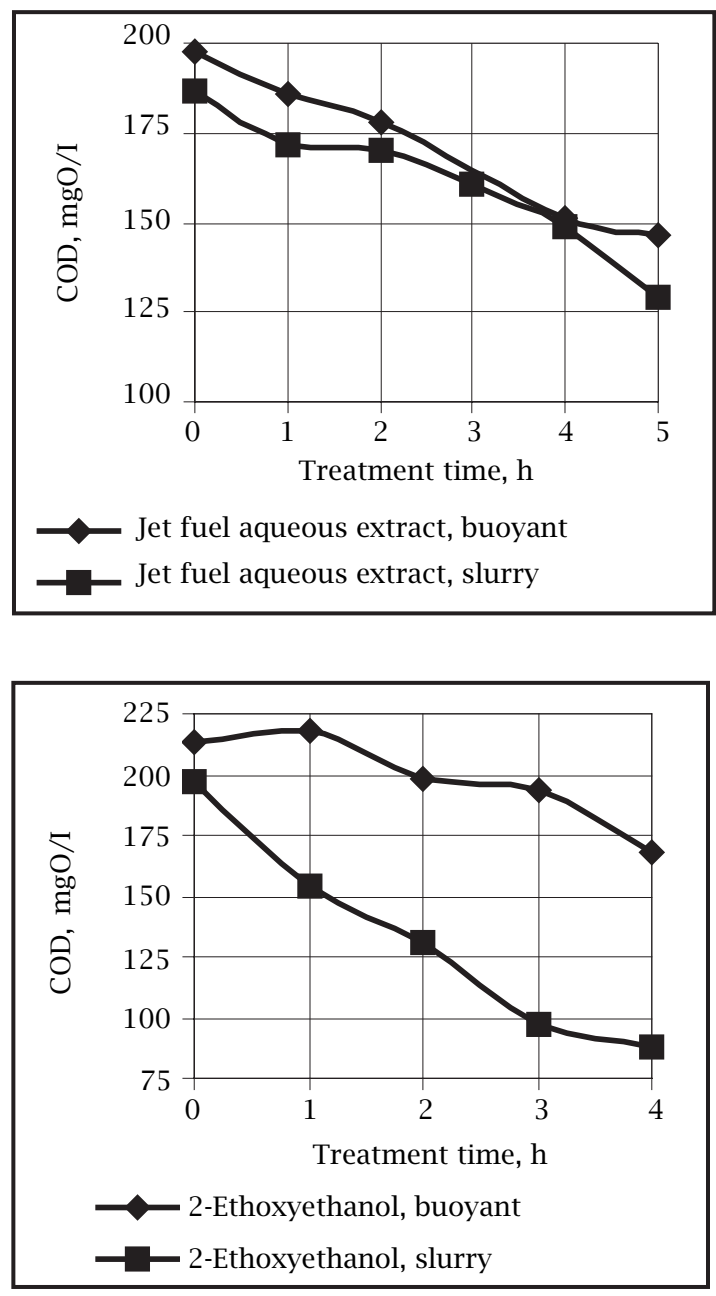

Figure 8. Dependence of jet fuel aqueous extract and 2-EE solutions COD on treatment time under solar radiation with buoyant catalyst and in $\mathrm{TiO}_{2}$ slurry.

PCO efficiency with non-agitated $\mathrm{TiO}_{2}$ slurry still noticeably higher than with the buoyant photocatalyst. This difference has an effect on the solar PCO rate, as shown in Figure 8.

3.6. Biodegradability of PCO products. An improvement in the biodegradability of aqueous solutions of icing inhibitors was previously observed in our studies [17]. Experiments for PCO's influence of subsequent biodegradability of MTBE solutions were carried out under the following conditions: 2 hours of treatment in agitated $\mathrm{TiO}_{2}$ slurry at $\mathrm{pH}$ 4.5. As a result of PCO of MTBE, biodegradability expressed as a $\mathrm{BOD}_{7} / \mathrm{COD}$ ratio increased from zero to 0.3 , which may be explained by the generation of biodegradable oxidation by-products.

\section{CONCLUSION}

MTBE readily yields to photocatalytic oxidation. A slightly acidic medium is preferable for process 
efficiency. Aldehydes were detected as MTBE PCO byproducts. PCO by-products are readily biodegradable: the BOD/COD ratio increased as PCO proceeded.

The addition of TBA as a radical scavenger to the sample of 2-EE solution resulted in a reduction of the PCO efficiency predominantly in the alkaline medium, which indicated that the radical mechanism plays a certain, although not dramatic, role in PCO of 2-EE.

PCO efficiency was observed to increase with increasing concentration of MTBE and 2-EE with no maximum achieved up to $2000 \mathrm{mg} / \mathrm{l}$. The character of the dependency looks typical for a Langmuir-Hinschelwood description of reaction kinetics.

The presence of calcium hydroxide in the $\mathrm{TiO}_{2}$ slurry noticeably increased the PCO efficiency. Addition of sulphate ions caused a decrease in PCO efficiency for MTBE. The presence of manganese and ferric ions at a concentration of $1 \mathrm{mM}$ improved the PCO efficiency of MTBE. Further addition of these ions up to $10 \mathrm{mM}$ resulted in a decrease in PCO efficiency. It was observed that further increase in the manganese and ferric ion concentrations up to $100 \mathrm{mM}$ initiated a different mechanism of the organic pollutant PCO and the initial MTBE PCO efficiency was restored.

The decrease in PCO efficiency of 2-EE due to reduced stirring appeared to be independent of $\mathrm{pH}$. We found that UV-transparent de-icing agents may be effectively removed from the solution by PCO with reduced or even no stirring of $\mathrm{TiO}_{2}$ slurries. Application of a buoyant photocatalyst appeared to be justified in the treatment of jet fuel aqueous extract due to its UV screening properties.

\section{ACKNOWLEDGEMENTS}

The authors express their gratitude to the Maj and Tor Nessling Foundation (Finland) and Estonian Science Foundation (grants Nr 4031 and 4866) for financial support of the present research. The assistance of Miss Marta López Velasco, a scholar from the University of Barcelona, in the experimental part of this research was greatly appreciated.

\section{REFERENCES}

[1] M. Metsur, M. Salu, V. Keerberg, and L. Tamm, Tapa lennuvälja puhastustööd 1998. aastal. (Treatment of Tapa former military airbase groundwater in 1998). Maves Ltd., Tallinn, Estonia (in Estonian), 1998.
[2] K. K. Papok, Motor, Jet and Rocket Fuels (Motornyje, reaktivnyje i raketnyje topliva). Gostoptehizdat, Moscow (in Russian), 1962.

[3] R. Johnson, J. Pankow, D. Bender, C. Price, and J. Zogorski, Env. Sci. Techn. News, May 1 (2000), 2A.

[4] P. Johnson, Environ. Sci. Technol. 32(2) (1998), 276.

[5] P. Bradley, J. Landmeyer, and F. Chapelle, Environ. Sci. Technol. 33(11) (1999), 1877.

[6] J. Eweis, D. Chang, E. Schroeder, K. Scow, R. Morton, and R. Caballero, Meeting the challenge of MTBE biodegradation. Proc. 90th Air \& Waste Management Assoc. Ann. Meeting, June 8-13, Toronto, Canada, 1997, p. 11.

[7] C. Yeh and J. Novak, Wat. Environ. Res. 66(5) (1994), 744.

[8] A. Keller, B. Bierwagen, S. Sirivithayapakorn, and M. Kram, Advances in groundwater treatment to remove MTBE. Hazardous and Industrial Wastes, Proc. $31^{\text {st }}$ Mid-Atl. Ind. Waste Conf., June 20-23, Storss, CT, USA, 1999, p. 199.

[9] J.-N. Chen, Y.-C. Chan, and M.-C. Lu, Water Sci. Technol. 39(10-11) (1999), 225.

[10] V. Brezova, A. Blazkova, E. Borosova, M. Ceppan, and R. Fiala, J. Molec. catal. 98 (1995), 109.

[11] J.-C. D’Oliveira, C. Guillard, C. Maillard, and P. Pichat, J. Environ. Sci. Health A 28(4) (1993), 941.

[12] M. Bekbölet, Z. Boyacioglu, and B. Özkaraova, Wat. Sci. Tech. 38(6) (1998), 155.

[13] Z. Hua, Z. Manping, X. Zongfeng, and G. K.-C. Low, Wat. Res. 29 (1995), 2681.

[14] N. B. Jackson, C. M. Wang, Z. Luo, J. Schwitzgebel, J. G. Ekerdt, J. R. Brock, and A. Heller, Journ. Electrochem. Soc. 138 (1991), 3660.

[15] Standard Methods for the Examination of Water and Wastewater. 19th edn, Am. Publ. Health Assoc./Am. Wat. Works Assoc./Wat. Environ. Fed., Washington DC, USA. 1995.

[16] W. H. Evans and A. Dennis, Analyst 98 (1973), 782.

[17] M. Krichevskaya, T. Malygina, S. Preis, and J. Kallas, Wat. Sci. Tech. 44(5) (2001), 1.

[18] S. Preis, M. Krichevskaya, Y. Terentyeva, A. Moiseev, and J. Kallas, Journ. Adv. Oxid. Technol. 5 (2002), 77.

[19] B. Faust and J. Hoigne, Atmos. Environ. 24 (1990), 79.

[20] X. Chen, H. Cheng, and J. Ma, Powder Technology 99 (1998), 171. 


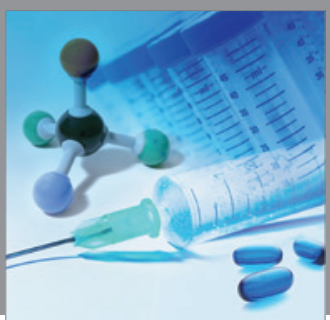

International Journal of

Medicinal Chemistry

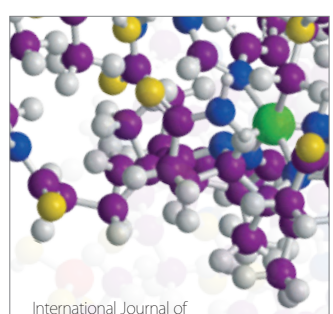

Carbohydrate Chemistry

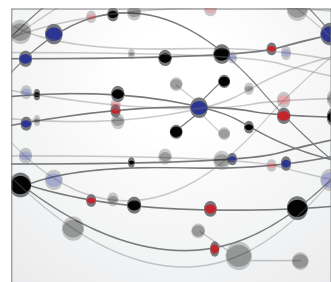

The Scientific World Journal
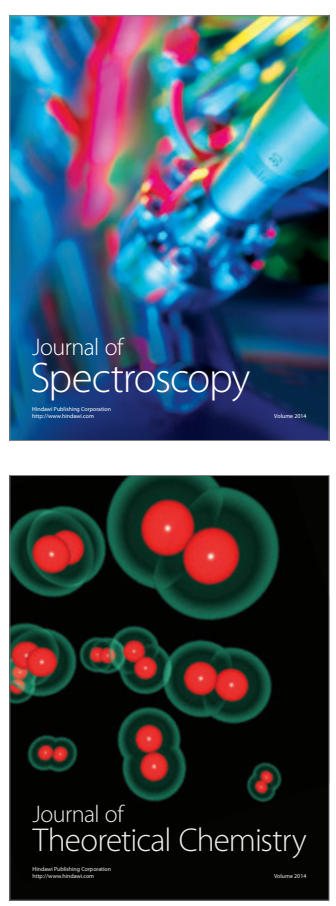
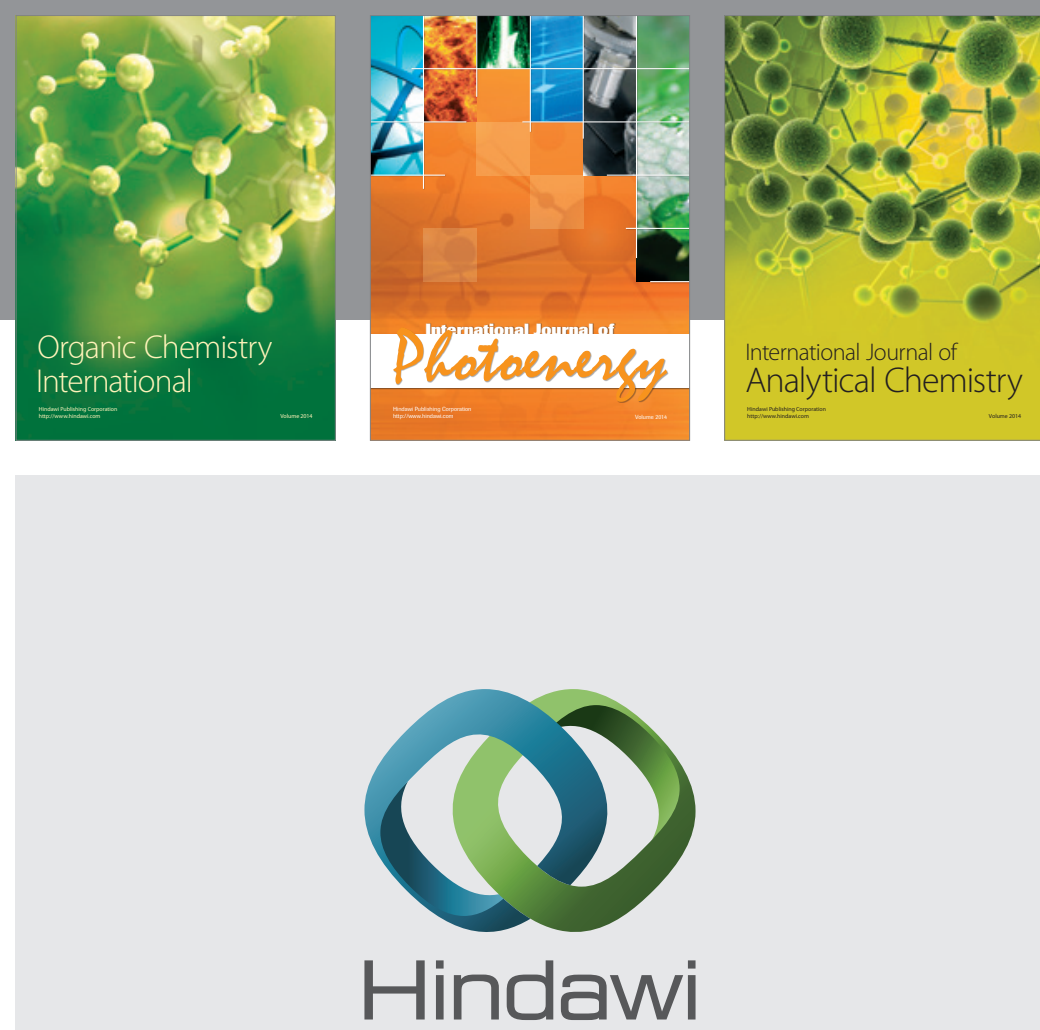

Submit your manuscripts at

http://www.hindawi.com
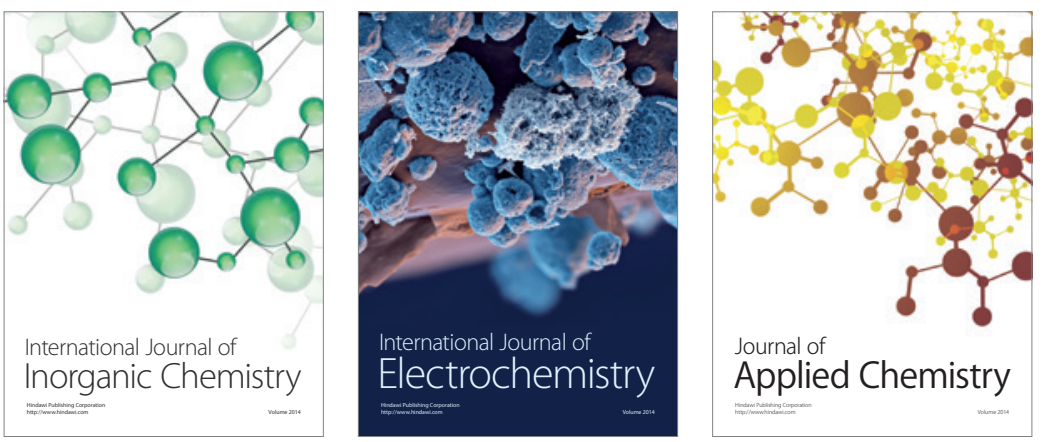

Journal of

Applied Chemistry
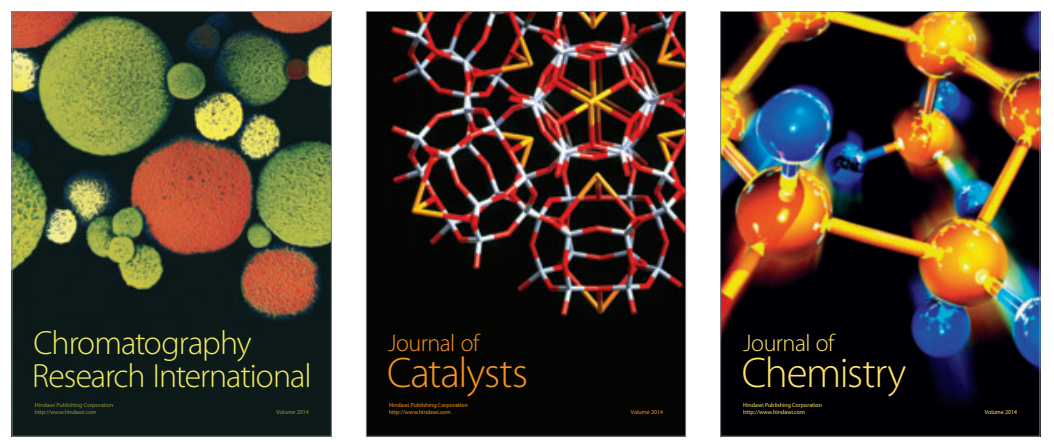
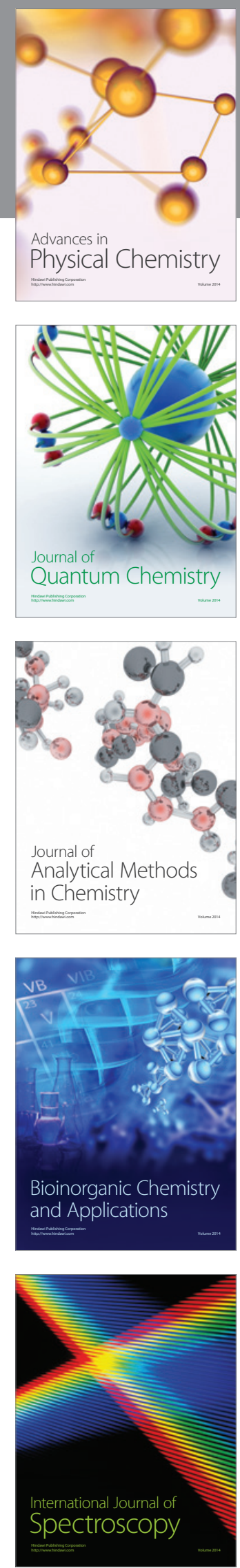